\title{
Endoscopic-assisted rib cartilage harvesting for revision rhinoplasty
}

\author{
Abdülkadir Göksel ${ }^{1}$, Emre Ilhan ${ }^{2}$ \\ ${ }^{1}$ Rinolstanbul Clinic, Istanbul 34740, Turkey. \\ ${ }^{2}$ RinoCenter Clinic, Istanbul 34740, Turkey.
}

Correspondence to: Dr. Abdülkadir Göksel, Rinolstanbul Clinic, Bağdat Cad. Zümrüt Apt. No. 378, Istanbul 34740, Turkey.

E-mail:akgoksel@gmail.com

How to cite this article: Göksel A, Ilhan E. Endoscopic-assisted rib cartilage harvesting for revision rhinoplasty. Plast Aesthet Res 2019;6:17. http://dx.doi.org/10.20517/2347-9264.2019.12

Received: 12 Mar 2019 First Decision: 5 Jun 2019 Revised: 15 Jul 2019 Accepted: 21 Jul 2019 Published: 29 Jul 2019

Science Editor: Hong Ryul Jin Copy Editor: Cai-Hong Wang Production Editor: Tian Zhang

\begin{abstract}
We describe the endoscopic-assisted rib harvesting technique for secondary rhinoplasty as minimum - invasive and safe harvesting method. Endoscopic-assisted rib harvesting was performed on 52 patients for revision rhinoplasty in last two years (2017-2019). Adequate amount of cartilage was obtained through 1-2 cm incision. The 30 degrees angled endoscope was used for vision control. Fifty-two patients underwent rhinoplasty with costal cartilage harvested using endoscopic-assisted method. The length of the harvested cartilage blocks from the rib was $5 \pm 1.5 \mathrm{~cm}$ in average. There were no associated intraoperative complications. Postoperative complications were less than by the conventional rib harvesting technique: in all cases, no signs of pneumothorax or excessive bleeding were detected after surgery. The wound healed without significant scarring in 50 (96\%) cases. Two patients (4\%) showed hypertrophic scar formation. Postoperative pain was evaluated by using Visual Pain Analog Scale retrospectively. Forty-eight patients (92\%) scored $1.43 \pm 0.7$ experienced no significant postoperative pain. Only 4 patients ( $8 \%$ ) scored $4.1 \pm 0.8$ and complained of slight postoperative pain. This technique provides an effective and less-invasive alternative for conventional costal cartilage harvesting with reduced complications risk and extended visualization. Patients benefit from an inconspicuous scar and reduced postoperative pain. Technique can be applied for revision and primary rhinoplasty and allows achieving reproducible aesthetically and functionally successful results with minimized risks.
\end{abstract}

Keywords: Rhinoplasty, rib, revision, costal cartilage

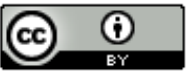

(C) The Author(s) 2019. Open Access This article is licensed under a Creative Commons Attribution 4.0 International License (https://creativecommons.org/licenses/by/4.0/), which permits unrestricted use, sharing, adaptation, distribution and reproduction in any medium or format, for any purpose, even commercially, as long as you give appropriate credit to the original author(s) and the source, provide a link to the Creative Commons license, and indicate if changes were made. 


\section{INTRODUCTION}

Nasal framework reconstruction in secondary and more rarely in primary rhinoplasty is often restricted by quantity and quality of cartilaginous framework. The most commonly used donor site for cartilage harvesting is considered to be septal cartilage, however surgeons frequently face such problems as: paucity of available graft material, especially in secondary cases and cartilaginous insufficiency in severe deformities cases. Both arguments are particularly true in secondary rhinoplasty when over resection of the osseocartilaginous framework is observed. Considering all these surgeons may often need an alternative source of grafting material in order to correct both aesthetic deformities and functional problems.

Satisfactory and consistent long-term results rely on using not only adequate quantity of cartilage, but also on graft quality: low resorption rate, sufficient strength for appropriate support, rejection and allergy safety. Thus, the most suitable and preferred graft material nowadays is considered to be autologous tissue. From all potential donor sites for autologous graft, the rib provides the most abundant cartilage source for graft fabrication and is the material of choice when reliable support is required ${ }^{[1]}$.

Conventional rib harvesting techniques included $3-5 \mathrm{~cm}$ incision and cutting the muscles ${ }^{[2]}$. Nevertheless, autogenous graft harvesting is associated with several disadvantages such as postoperative pain, visible scar, risk of pleura perforation and often requires advanced surgical skills ${ }^{[3,4]}$. With regard to above mentioned complexities, we suggest the method of endoscope-assisted rib cartilage harvesting. This technique is less invasive and enables reducing risks of bleeding and pleura perforation due to extended visualization and better remote access incision site.

In last two years we performed 52 endoscopic-assisted rib harvesting. We observed significant decrease in postoperative pain, bleeding and therefore faster recovery and better aesthetic result.

\section{ENDOSCOPIC RIB HARVESTING OPERATIVE TECHNIQUE}

\section{Marking}

Rib cartilage harvesting is preferentially performed on the patient's right side. Marking starts with palpating the sternomanubrial junction, which corresponds to the position of the second rib. The ribs are then numbered according to their position. We prefer to harvest 6th rib as it provides abundant cartilage supply and is straight and wide enough for future graft fabrication.

Placement of the incision line is determined by the sex of the patient. In female patients, the inframammary fold offers a good position for camouflage and the incision line is marked at approximately $5 \mathrm{~mm}$ above the inframammary fold ${ }^{[5]}$. The incision should not extend beyond the medial border of the inframammary fold in order to avoid postoperative visibility. In male patients, the incision is placed right over the selected rib.

\section{Incision}

The main advantage of this method is short incision, about 1-2 cm [Figure 1]. Some experienced surgeons do harvest the rib through such small incision with direct vision without using endoscope, but usually it requires advanced surgical skills and is still associated with bad visualization and, therefore, higher risk of pneumothorax and bleeding for the not enough experienced surgeons.

When placement of the incision is chosen, harvesting procedure begins by incising the skin using 15th blade. The subcutaneous and fascial layers are transected using electrocautery or blade. The muscle itself was not cut, instead, it was divided bluntly by spreading following the direction of the muscle fibers. Dissection was concluded with Freer elevators. This step enables to reduce postoperative pain and possible intraoperative bleeding ${ }^{[6]}$ [Figure 2]. 


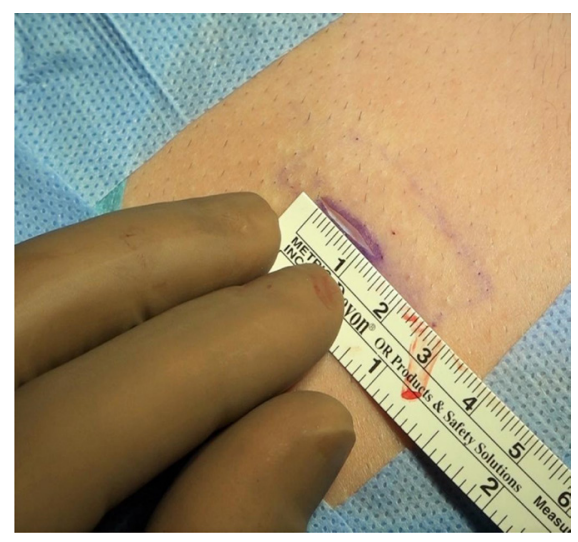

Figure 1. Incision $1.2 \mathrm{~cm}$ in length

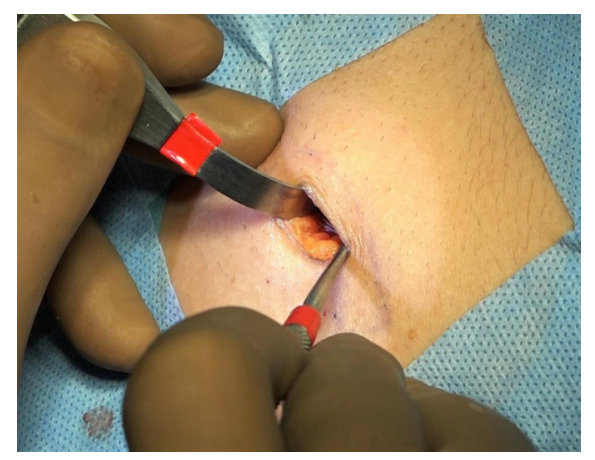

Figure 2. Separating the muscle fibers via blunt dissection

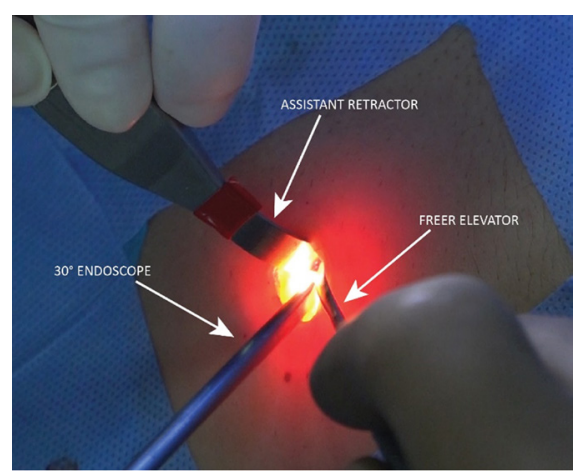

Figure 3. Using the endoscope - surgeon is holding the endoscope with left arm. Second arm is holding the elevator. Assistant is helping to open the wound with the retractor

\section{Endoscopic-controlled harvesting}

Once the muscles are separated, we are able to see the rib clearly. Assistant retract the wound upward to make room for endoscopic work. We use 30 degrees angled endoscope. Surgeon is holding endoscope with one hand, while using Freer elevator with the other hand. Other instrument may be used if needed [Figure 3].

Then we reach the rib with the help of endoscope, which gives us clear wound imaging. Now, one can see the perichondrium clearly [Figure 4]. It's crucial to know the position of both sided bony cartilaginous junctions for ensuring that the maximum possible length of the cartilage is harvested, thereby optimizing the efficiency of the procedure. 


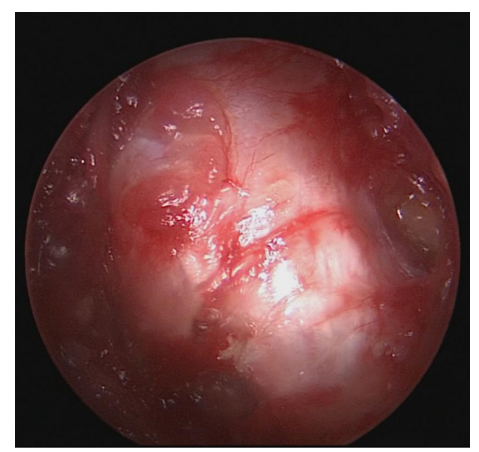

Figure 4. Clear visualization of the perichondrium with the help of endoscope

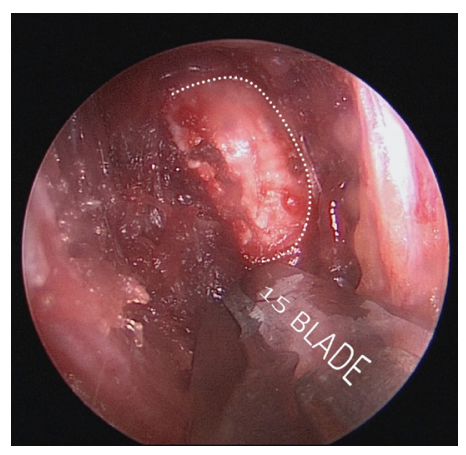

Figure 5. Perichondrial flap

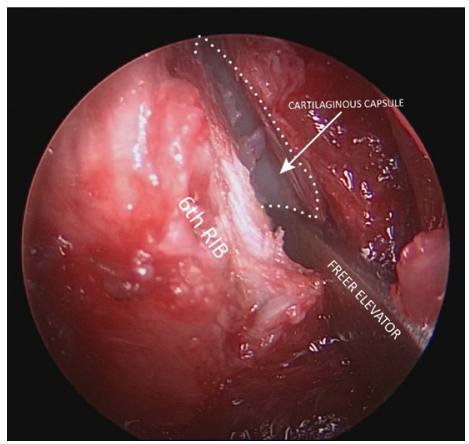

Figure 6. Elevation of the perichondrium

Then, we are making a so-called "window" incision to the perichondrium - creating a quadrangular perichondrial flap, with its 3 from 4 sides incised [Figure 5].

After perichondrium elevation one should pay attention to another tissue layer - under the perichondrium there is a thin layer of cartilaginous capsule. In order to perform the procedure safe in a bloodless plain, surgeon has to be under the capsule. Once the layer beneath is approached - one is safe for performing the dissection [Figure 6].

We perform the whole dissection using Freer elevator in my second hand, although it's not a must Dissection is limited by the junction of the rib cartilage and the sternum medially, and by demarcated costochondral zone laterally. Both can be clearly seen via endoscope. 


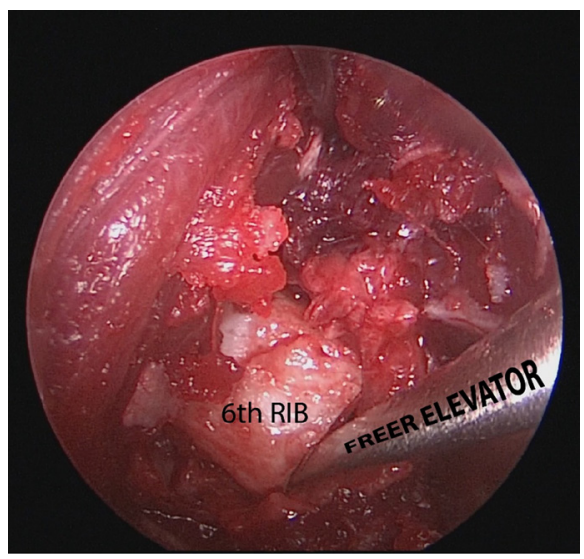

Figure 7. Disarticulation of the rib

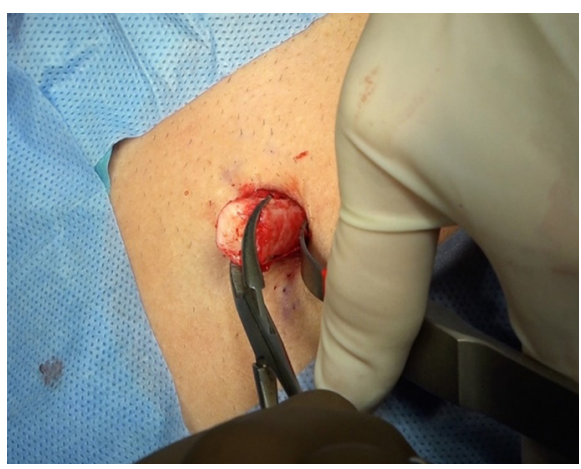

Figure 8. Cartilage is easily removed from the wound after disarticulation

During capsule elevation care must be taken to not enter the cartilage, harm the cartilaginous surface or cause the fracture that may limit future graft fabrication.

When undermining is completed right-angled circular incision to the cartilage is performed using 15th blade. We make semi-circular incision on one side first, then we turn around the rib and finish the incision connecting both lines.

After incision is made the cartilage segment is released both medially and laterally by means of disarticulation using Freer elevator [Figure 7].

Cartilage is easily removed from the wound and placed in sterile saline solution until the graft fabrication [Figure 8].

\section{Calcified cartilage}

Despite appropriate preoperative screening, occasionally patients may present with premature calcification of the cartilaginous rib. Frequently, the main calcification area can be observed at the junction of the osseous and cartilaginous rib.

In most of cases, one can manage this problem using the elevator to gently lift the calcification for providing an adequate access to the underlying cartilage. But in some more severe cases, usually by elder patients, calcification is too strong and tightly welded to the rib. In such cases the use of Piezo electric device has 


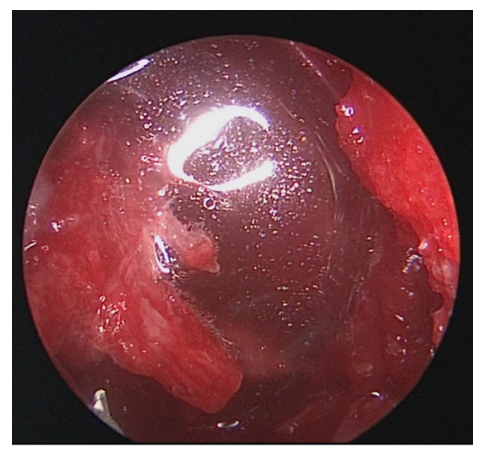

Figure 9. Insufflation test - filling the wound with saline solution

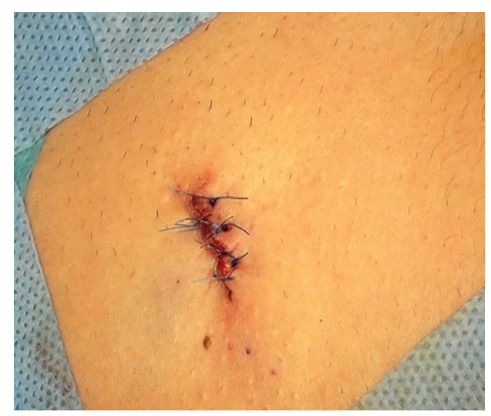

Figure 10. Closed wound. Separate skin sutures using 5.0 prolene

proven to be very helpful in contouring areas of calcification. In this situation, we prefer to enlarge the incision and use piezo electric instrument under direct vision because it's not easy to use piezo device with endoscopic view. As the Piezo electric device does not harm any soft tissue, one can be safely cut out the calcified area without injuring the perichondrium ${ }^{[7]}$.

Small calcifications may also be found within the body of the rib cartilage itself. This fact should be drawn to surgeon's attention as it can impair the preparation of individual grafts and act as a site of weakness, often having a tendency to fracture.

\section{Safety check}

After cartilage removal it's important to make sure that pleura is left intact. We perform insufflation test filling the wound with saline solution and using positive thoracic pressure ${ }^{[6]}$. If no bubbles observed- one is safe and pleura is intact. After the test we wash the cavity with rifampicin solution [Figure 9].

\section{Wound closure}

We close the wound layer by layer for faster healing and avoiding tension. Closure is initiated from perichondral layer by putting 2-3 stitches with 4.0 rapid vicryl. Then the subcutaneous layer is closed with 4.0 vicril.

Skin is closed with separate sutures using 5.0 prolene. We haven't used any drain application on any of our cases [Figure 10].

\section{Graft fabrication}

We suggest to use the rib according to the oblique split method, described by Dr. Eren Tastan [Figure 11]. As warping has been the main problem by costal cartilage grafting, oblique split method provides straight costal cartilage grafts of varying thicknesses without the risk of warping. 


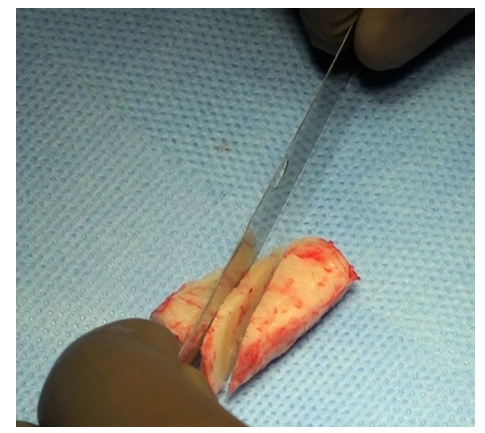

Figure 11. Cutting harvested cartilage according to oblique split method

Numerous clinical cases have shown that a cross-sectional graft obtained through an oblique cut to the long axis of the rib results in a graft with equal circumferential forces of contracture that have a decreased chance of warping ${ }^{[8]}$.

\section{Postoperative pain}

Usually the main patient's complain after conventional rib harvesting is postoperative pain. Due to the fact that thoracic muscles are used for such physiological process as breathing and many other everyday activities such as getting up, speaking, walking and so forth - the thorax cannot be immobilized completely in postoperative period. In the majority of cases these movements may cause pain conditioned by the cut muscle fibers.

On the contrary, one of the key advantages of the endoscopic rib harvesting is reduced postoperative pain. Significant decrease in pain is attained by means of delicate muscle undermining under endoscopic-assisted vision, which enables to preserve the majority of muscle fibers. The use of muscle-sparing technique contributes to faster healing with reduced postoperative pain [1.6 \pm 0.9 Visual Pain Analog Scale (VAS)]. This benefit is more pronounced in the early postoperative period and is especially dramatic in reducing movement pain ${ }^{[6]}$.

\section{OUR EXPERIENCE}

The endoscopic-assisted rib harvesting was performed on 52 patients in last two years. In all cases no severe complications such as pneumothorax or excessive bleeding was observed. The incision length was $1.4 \pm 0.3 \mathrm{~cm}$ in average. Fifty patients (96\%) showed no problems with scar healing and 2 patients (4\%) showed hypertrophic scar formation. Postoperative pain was evaluated by using VAS retrospectively. Forty-eight patients $(92 \%)$, who scored $1.43 \pm 0.7$ experienced no significant postoperative pain. Only 4 patients who scored $4.1 \pm 0.8(8 \%)$ complained of slight postoperative pain for the first 2-3 days and it was manageable with Paracetamol $1000 \mathrm{mg} \mathrm{i} / \mathrm{v}$. In this cases pain was relieved with no additional painkillers or local anesthetic agent. Dissection was done with Freer elevators, which also enabled to reduce postoperative pain and possible intraoperative bleeding ${ }^{[6]}$. Recovery to walk and breath normally was very short showing $1.2 \pm 0.6$ days. Patients did not need additional rehabilitation and recovery exercises and precautions. With regard to our clinical study this method allows achieving reproducible, aesthetically and functionally successful results with minimized risks.

\section{CONCLUSION}

Rib cartilage harvest is a common procedure in primary and secondary rhinoplasties. The main disadvantages of the conventional technique for autogenous graft harvesting are risks of potential complications such as bleeding, pneumothorax, and postoperative pain. 
Using endoscopic system in harvesting the rib cartilage provides better visuality and safety with less chance for major complications by conventional methods although this method requires surgeon's experience in using endoscope and has limitations in overweight patients.

\section{DECLARATIONS}

\section{Authors' contributions}

Made substantial contributions to conception and design of the study and performed data analysis and interpretation: Göksel A

Provided technical, and material support: Ilhan E

\section{Availability of data and materials}

Not applicable.

\section{Financial support and sponsorship}

None.

\section{Conflicts of interest}

All authors declared that there are no conflicts of interest.

\section{Ethical approval and consent to participate}

Not applicable.

\section{Consent for publication}

Written informed consent for publication was obtained from patients mentioned in article and added photos.

\section{Copyright}

(c) The Author(s) 2019.

\section{REFERENCES}

1. Parker Porter J. Grafts in rhinoplasty: alloplastic vs. autogenous. Arch Otolaryngol Head Neck Surg 2000;126:558-61.

2. Marin VP, Landecker A, Gunter JP. Harvesting Rib cartilage grafts for secondary rhinoplasty. Plast Reconstr Surg 2008;121:1442-8.

3. Wee JH, Park MH, Oh S, Jin HR. Complications associated with autologous rib cartilage use in rhinoplasty: ameta-analysis. JAMA Facial Plast Surg 2015; 17:49-55.

4. Woo KJ, Kang BY, Min JJ, Park JW, Kim A, et al. Postoperative pain control by preventive intercostal nerve block under direct vision followed by catheter-based infusion of local analgesics in rib cartilage harvest for auricular reconstruction in children with microtia: a randomized controlled trial. J Plast Reconstr Aesthet Surg 2016;69:1203-10.

5. Toriumi DM. Dorsal augmentation using autologous costal cartilage or microfat-infused soft tissue augmentation. Facial Plast Surg 2017;33:162-78.

6. Özücer B, Dinç ME, Paltura C, Koçak I, Dizdar D, et al. Association of autologous costal cartilage harvesting technique with donor-site pain in patients undergoing rhinoplasty. JAMA Facial Plast Surg 2018;20:136-40.

7. Gerbault O, Daniel RK, Kosins AM. The role of piezoelectric instrumentation in rhinoplasty surgery. Aesthet Surg J 2016;36:21-34.

8. Taştan E, Yücel ÖT, Aydin E, Aydoğan F, Beriat K, et al. The oblique split method a novel technique for carving costal cartilage grafts. JAMA Facial Plast Surg 2013;15:198-203. 